\title{
Social acceptability and desirability of smoking in a national sample of Aboriginal and Torres Strait Islander people
}

$\mathrm{S}$ moking is partly motivated by social factors, although the strength of this influence has declined as smoking has become less socially normative in the community. ${ }^{1,2}$ Social norms have two aspects: social acceptability, or the contexts where the behaviour is accepted, and social desirability, or the extent to which it is valued. Separating the two can be difficult in practice.

Challenging normative beliefs was a focus of community-based programs to reduce the smoking rate and burden of tobacco-related disease among Aboriginal and Torres Strait Islander communities, ${ }^{3}$ as part of the 2009 National Partnership Agreement on Closing the Gap in Indigenous Health Outcomes. ${ }^{4}$ In particular, these programs tackled the social desirability and acceptability of smoking in contexts where the smoke affects other people. There has been very little published research to guide this approach.

In the broader Australian population, most smokers (86\%) agree that society disapproves of smoking, ${ }^{5}$ which is an indication that smoking is no longer socially acceptable in certain situations. In contrast, the high prevalence of smoking in Aboriginal and Torres Strait Islander peoples $(42 \%$ in those aged 15 years or older $)^{6}$ contributes to beliefs that smoking is normal, expected or intergenerational. ${ }^{7-12}$ This suggests a certain level of acceptability but does not necessarily indicate whether smoking is socially desirable or valued.

Menzies School of Health Research, Darwin, NT.

2 Cancer Council Victoria Melbourne, VIC.

3 University of Melbourne Melbourne, VIC.

4 Queensland Aboriginal and Islander Health Council, Brisbane, QLD.

anna.nicholson@ menzies.edu.au

doi: 10.5694/mjal4.01534

\section{Abstract}

Objectives: To describe social normative beliefs about smoking in a national sample of Aboriginal and Torres Strait Islander people, and to assess the relationship of these beliefs with quitting.

Design, setting and participants: The Talking About The Smokes project used a quota sampling design to recruit participants from communities served by 34 Aboriginal community-controlled health services and one community in the Torres Strait. We surveyed 1392 daily smokers, 251 nondaily smokers, 311 ex-smokers and 568 never-smokers from April 2012 to October 2013.

Main outcome measures: Eight normative beliefs about smoking; wanting and attempting to quit.

Results: Compared with daily smokers in the general Australian population, Aboriginal and Torres Strait Islander daily smokers were less likely to report that mainstream society disapproves of smoking (78.5\% v 62\%). Among Aboriginal and Torres Strait Islander daily smokers, $40 \%$ agreed that Aboriginal and Torres Strait Islander community leaders where they live disapprove of smoking, 70\% said there are increasingly fewer places they feel comfortable smoking, and most ( $90 \%$ ) believed non-smokers set a good example to children. Support for the government to do more to tackle the harm caused by smoking was much higher than in the general Australian population ( $80 \%$ v $47.2 \%$ ). These five normative beliefs were all associated with wanting to quit. Non-smokers reported low levels of pressure to take up smoking.

Conclusion: Tobacco control strategies that involve the leadership and participation of local Aboriginal and Torres Strait Islander community leaders, particularly strategies that emphasise protection of others, may be an important means of reinforcing beliefs that smoking is socially unacceptable, thus boosting motivation to quit.

identified as important anti-tobacco role models for Aboriginal and Torres Strait Islander youth.-9

However, there is evidence that smoking is also valued within Aboriginal and Torres Strait Islander networks, among which smoking and sharing tobacco are associated with connectedness, affirmation of cultural identity and the opportunity to talk through problems. ${ }^{79,11-13,15,16}$ The strength of these competing values and their influence on quitting has not been previously investigated.

Here, we describe social normative beliefs about smoking in a national sample of Aboriginal and Torres Strait Islander peoples, and assess the relationship of these beliefs with quitting.

\section{Methods}

\section{Survey design and participants}

We used data from the Talking About The Smokes (TATS) project, which conducted baseline surveys of 2522 Aboriginal and Torres Strait Islander people (1643 current smokers, 311 ex-smokers and 568 never-smokers) from April 2012 to October 2013. The survey design and participants have been described in detail elsewhere. ${ }^{17,18}$

Briefly, the study used a quota sampling design to recruit participants from communities served by 34 Aboriginal community-controlled health services (ACCHSs) and one community in the Torres Strait. These project sites were selected based on the population distribution of Aboriginal and Torres Strait Islander people by state or territory 
and remoteness. In most sites (30/35), we aimed to interview a sample of 50 smokers (or ex-smokers who had quit $\leqslant 12$ months previously) and a smaller sample of 25 non-smokers, with equal numbers of men and women, and those aged $18-34$ and $\geqslant 35$ years. The sample sizes were doubled in four major urban sites and the Torres Strait. People were excluded if they were less than 18 years old, were not usual residents of the area, were staff of the ACCHS, or were deemed unable to consent or complete the survey.

In each site, different locally determined methods were used to collect a representative, albeit non-random, sample. The baseline sample closely matched the sample distribution of the 2008 National Aboriginal and Torres Strait Islander Social Survey (NATSISS) by age, sex, jurisdiction and remoteness, and number of cigarettes smoked per day (for current daily smokers). However, there were inconsistent differences in some socioeconomic indicators: our sample had higher proportions of unemployed people, but also higher proportions who had completed Year 12 and who lived in more advantaged areas. ${ }^{17}$

Interviews were conducted face to face by trained interviewers, almost all of whom were members of the local Aboriginal and Torres Strait Islander community. The survey, entered directly onto a computer tablet, took 30-60 minutes to complete. A single survey of health service activities was also completed for each site.

The project was approved by three Aboriginal human research ethics committees (HRECs) and two HRECs with Aboriginal subcommittees: Aboriginal Health \& Medical Research Council Ethics Committee, Sydney; Aboriginal Health Research Ethics Committee, Adelaide; Central Australian HREC, Alice Springs; HREC for the Northern Territory Department of Health and Menzies School of Health Research, Darwin; and the Western Australian Aboriginal Health Ethics Committee, Perth.

\section{ITC Project comparison sample}

The TATS project is part of the International Tobacco Control Policy
Evaluation Project (ITC Project) collaboration. Comparisons were made with smokers in the general Australian population using data from the Australian ITC project, which surveyed 1010 daily smokers between September 2011 and February 2012 (Wave 8.5). Participants of the Australian ITC project were recruited by random digit telephone dialling from within strata defined by jurisdiction and remoteness. ${ }^{19}$ While baseline surveys were completed over the telephone, follow-up surveys could be completed online. Our comparisons are for daily smokers only, due to slightly different definitions of non-daily smokers between the TATS project and ITC Project surveys.

\section{Outcome measures}

Survey questions were based on previous Australian ITC Project surveys, but with added questions about specific concerns and in language better reflecting Aboriginal and Torres Strait Islander colloquial speech. Eight questions assessed normative beliefs, all of which used a five-point scale ranging from "strongly agree" to "strongly disagree" (plus a "don't know" response, which was later merged with "neither agree nor disagree", and a "refused" option, which was excluded from analysis).

Two quit-related outcomes were used: wanting to quit, and having attempted to quit in the past year, which was derived from questions on ever having tried to quit and how long ago the most recent quit attempt occurred. The exact survey questions are presented in Appendix 1.

\section{Statistical analyses}

We calculated percentages and frequencies for all normative belief items. ITC Project data were summarised using percentages and 95\% confidence intervals, directly standardised to match the age and sex profile of Aboriginal and Torres Strait Islander smokers according to the 2008 NATSISS.

For TATS project outcomes, variation by smoking status was investigated with simple logistic regression. Multivariable logistic regression was used to assess the association of each normative belief with wanting and attempting to quit, adjusted for daily smoking status and key sociodemographic variables. Stata 13 (StataCorp) survey [SVY] commands were used to adjust for the TATS Project sampling design, identifying the 35 project sites as clusters and the age-sex quotas as strata. ${ }^{20}$

For questions about normative beliefs, data were excluded for less than $1 \%$ of participants due to missing or refused responses. For associations with wanting to quit, we excluded a further 79 smokers ( $4.8 \%$ ) who did not know if they wanted to quit; and for associations with quitting in the past year, we excluded 21 (1.3\%) who did not know when their last quit attempt occurred (if ever).

\section{Results}

\section{Normative beliefs}

Aboriginal and Torres Strait Islander daily smokers were less likely than those in the general Australian population to perceive that mainstream society disapproves of smoking $(62 \% \mathrm{v}$ $78.5 \%$ ) (Box 1). Among all Aboriginal and Torres Strait Islander respondents, higher proportions agreed that society disapproves of smoking than agreed that Aboriginal and Torres Strait Islander community leaders where they live disapprove of smoking (62\% v 41\%).

While similar proportions of daily and non-daily smokers agreed that mainstream society disapproves of smoking, non-daily smokers were more likely to agree that Aboriginal and Torres Strait Islander community leaders where they live disapprove (odds ratio [OR], 1.50; 95\% CI, 1.10 2.05; $P=0.01$ ). Close to two-thirds of smokers and recent quitters agreed there are now fewer places where they feel comfortable smoking, with little variation by smoking status. Although a minority of respondents said nonsmokers miss out on all the gossip, this belief was more common among non-daily smokers (OR, 1.46; 95\% CI, $1.01-2.10 ; P=0.04)$ than daily smokers. Most Aboriginal and Torres Strait Islander respondents ( $90 \%$ or more) reported that being a non-smoker sets a good example to children, 
1 Social normative beliefs about smoking among daily smokers in the Australian population and among a national sample of Aboriginal and Torres Strait Islander people, by smoking status*

\begin{tabular}{|c|c|c|c|c|c|}
\hline \multirow[b]{2}{*}{ Normative belief ${ }^{\delta}$} & \multirow{2}{*}{$\begin{array}{l}\text { Australian ITC Project }{ }^{\dagger} \\
\begin{array}{c}\text { Daily smokers } \\
(n=1010)\end{array}\end{array}$} & \multicolumn{4}{|c|}{ Talking About The Smokes project ${ }^{\ddagger}$} \\
\hline & & $\begin{array}{l}\text { Daily smokers } \\
\quad(n=1392)\end{array}$ & $\begin{array}{c}\text { Non-daily } \\
\text { smokers }(n=251)\end{array}$ & $\begin{array}{l}\text { Ex-smokers } \\
\quad(n=311)\end{array}$ & $\begin{array}{l}\text { Never-smokers } \\
\quad(n=568)\end{array}$ \\
\hline \multicolumn{6}{|l|}{ [Mainstream] society disapproves of smoking } \\
\hline Strongly agree or agree & $78.5 \%(73.3 \%-82.9 \%)$ & $62 \%(851)$ & $65 \%(164)$ & $62 \%(190)$ & $62 \%(351)$ \\
\hline Neither agree nor disagree, or don't know & $10.6 \%(7.9 \%-13.9 \%)$ & $24 \%(336)$ & $22 \%(56)$ & $22 \%(67)$ & $24 \%(138)$ \\
\hline Disagree or strongly disagree & $11.0 \%(7.4 \%-15.9 \%)$ & $14 \%(196)$ & $12 \%(31)$ & $17 \%(52)$ & $14 \%(78)$ \\
\hline \multicolumn{6}{|c|}{$\begin{array}{l}\text { Aboriginal and/or Torres Strait Islander community leaders } \\
\text { where you live disapprove of smoking }\end{array}$} \\
\hline Strongly agree or agree & - & $40 \%(547)$ & $50 \%(124)$ & $43 \%(133)$ & $38 \%(218)$ \\
\hline Neither agree nor disagree, or don't know & - & $33 \%(453)$ & $24 \%(60)$ & $29 \%(88)$ & $36 \%(205)$ \\
\hline Disagree or strongly disagree & - & $28 \%(380)$ & $26 \%(66)$ & $28 \%(87)$ & $26 \%(145)$ \\
\hline \multicolumn{6}{|c|}{$\begin{array}{l}\text { There are fewer and fewer places you (would) feel } \\
\text { comfortable smoking }\end{array}$} \\
\hline Strongly agree or agree & - & $70 \%(970)$ & $65 \%(163)$ & $65 \%(51)$ & - \\
\hline Neither agree nor disagree, or don't know & - & $14 \%(192)$ & $14 \%(35)$ & $13 \%(10)$ & - \\
\hline Disagree or strongly disagree & - & $16 \%(220)$ & $21 \%(52)$ & $22 \%(17)$ & - \\
\hline \multicolumn{6}{|c|}{ Non-smokers miss out on all the good gossip/yarning } \\
\hline Strongly agree or agree & - & $27 \%(379)$ & $36 \%(89)$ & $29 \%(89)$ & $23 \%(131)$ \\
\hline Neither agree or disagree, or don't know & - & $18 \%(246)$ & $16 \%(41)$ & $8 \%(26)$ & $14 \%(81)$ \\
\hline Disagree or strongly disagree & - & $55 \%(758)$ & $48 \%(121)$ & $63 \%(194)$ & $63 \%(356)$ \\
\hline \multicolumn{6}{|c|}{ Being a non-smoker sets a good example to children } \\
\hline Strongly agree or agree & - & $90 \%(1246)$ & $94 \%(236)$ & $95 \%(292)$ & $95 \%(541)$ \\
\hline Neither agree nor disagree, or don't know & - & $5 \%(70)$ & $2 \%(5)$ & $2 \%(6)$ & $3 \%(15)$ \\
\hline Disagree or strongly disagree & - & $5 \%(67)$ & $4 \%(10)$ & $4 \%(11)$ & $2 \%(11)$ \\
\hline \multicolumn{6}{|c|}{$\begin{array}{l}\text { The government should do more to tackle the harm [done } \\
\text { to Aboriginal and Torres Strait Islander people] that is } \\
\text { caused by smoking }\end{array}$} \\
\hline Strongly agree or agree & $47.2 \%(41.6 \%-52.8 \%)$ & $80 \%(1108)$ & $86 \%(215)$ & $89 \%(270)$ & $84 \%(465)$ \\
\hline Neither agree nor disagree, or don't know & $21.6 \%(17.5 \%-26.3 \%)$ & $13 \%(173)$ & $9 \%(23)$ & $6 \%(17)$ & $12 \%(65)$ \\
\hline Disagree or strongly disagree & $31.3 \%(25.8 \%-37.3 \%)$ & $7 \%(101)$ & $5 \%(12)$ & $6 \%(18)$ & $4 \%(24)$ \\
\hline \multicolumn{6}{|c|}{$\begin{array}{l}\text { ITC Project = International Tobacco Control Policy Evaluation Project. * Percentages and frequencies exclude refused responses. † Results are percentages (95\% confidence intervals } \\
\text { for daily smokers from Wave } 8.5 \text { (September } 2011 \text { - February 2012) of the Australian ITC Project, directly standardised to the age and sex of Aboriginal and Torres Strait Islander } \\
\text { smokers surveyed in the } 2008 \text { National Aboriginal and Torres Strait Islander Social Survey. ₹Results are percentages (frequencies) for the baseline sample of Aboriginal and Torres } \\
\text { Strait Islander people in the Talking About The Smokes project (April 2012-October 2013). \$ Text in square brackets was not included in Australian ITC Project survey questions. } \\
\text { 9 Asked of smokers and recent quitters only. }\end{array}$} \\
\hline
\end{tabular}

with no clear difference by smoking status. Finally, there was overwhelming support ( $80 \%$ or higher) for the government doing more to tackle the harm to Aboriginal and Torres Strait Islander peoples caused by smoking. This was significantly higher than the level of support for government action among the general Australian population (47.2\%).

Few non-smokers said they were excluded by smokers or pressured by smokers to take up smoking (Box 2). Ex-smokers who had stopped smoking within the past year (but not those who had been quit for more than 1 year) were more likely to say they were pressured to smoke (OR, 1.99 ; 95\% CI, $1.09-3.61 ; P=0.04)$ than those who had never smoked.

\section{Relationship between normative beliefs and quitting}

Among smokers, all five anti-smoking beliefs were associated with wanting to quit, and all except perceived societal disapproval of smoking were also associated with having attempted to quit in the past year (Box 3). The only pro-smoking belief, that non-smokers miss out on all the gossip or yarning, was not associated with either wanting or attempting to quit.

\section{Discussion}

We found that Aboriginal and Torres Strait Islander smokers are less likely than smokers in the broader Australian population to believe that society views smoking as socially unacceptable. This difference is likely to be a product of higher smoking prevalence, but it may also reinforce it - lower perceived social acceptability of smoking was associated with wanting and attempting to quit, as has been found in other settings. ${ }^{21-24}$ In contrast, personal attitudes towards smoking (regretting starting to smoke, perceiving it to be too expensive, enjoying it, seeing it as an important part of life and smoking for stress management) do not appear to be driving differences in quitting. ${ }^{25}$

One possible interpretation of this pattern of results is that social norms are more influential in collectivist societies, in which behaviour is shaped to a greater degree by societal than 
2 Social normative beliefs about smoking in a national sample of Aboriginal and Torres Strait Islander non-smokers*

\begin{tabular}{lccc} 
Normative belief & $\begin{array}{c}\text { Ex-smokers quit } \\
\leqslant 1 \text { year }(n=78)\end{array}$ & $\begin{array}{c}\text { Ex-smokers quit } \\
>1 \text { year }(n=233)\end{array}$ & $\begin{array}{c}\text { Never-smokers } \\
(n=568)\end{array}$ \\
\hline $\begin{array}{l}\text { You are excluded from things because you are a } \\
\text { non-smoker (now) }\end{array}$ & $27 \%(21)$ & $25 \%(58)$ & $24 \%(137)$ \\
$\quad$ Strongly agree or agree & $8 \%(6)$ & $6 \%(14)$ & $13 \%(73)$ \\
$\quad$ Neither agree nor disagree & $65 \%(51)$ & $69 \%(159)$ & $63 \%(358)$ \\
$\quad$ Disagree or strongly disagree & & & \\
You are pressured by smokers to take up smoking & & & \\
(again) & $26 \%(20)$ & $13 \%(29)$ & $15 \%(84)$ \\
$\quad$ Strongly agree or agree & $3 \%(2)$ & $4 \%(10)$ & $8 \%(43)$ \\
$\quad$ Neither agree nor disagree & $72 \%(56)$ & $83 \%(192)$ & $78 \%(441)$ \\
$\quad$ Disagree or strongly disagree & & \\
* Results are percentages (frequencies) for the baseline sample in the Talking About The Smokes project (April 2012-October \\
2013) and exclude refused responses.
\end{tabular}

personal needs. ${ }^{24,26,27}$ There is a growing body of evidence that protecting others provides strong motivation for Aboriginal and Torres Strait Islander peoples to quit, ${ }^{7,13,14,28}$ reflected here in the particular salience and influence of believing non-smokers set a good example to children. Similar findings were reported for Maori and Pacific peoples in the New Zealand ITC Project, ${ }^{26}$ which recommended greater emphasis on social reasons to quit, such as setting an example to children. For those who work in comprehensive primary health care settings, messages framed in ways that emphasise protecting others are likely to motivate quitting for Aboriginal and Torres Strait Islander peoples who smoke.

However, while this may be a more effective means of motivating people to quit, the implications for sustaining quit attempts are unclear. Current behaviour change theory suggests that quitting may be more difficult to sustain when motivated by social influences (including concern for others), given the likely challenges by internal needs such as biological or psychological dependence. ${ }^{2}$ General practitioners and others who provide cessation help should not discount the possibility that more dependent smokers may require support to manage cravings or urges to smoke upon quitting. Sustaining a quit attempt in the face of additional challenges, some of which are specific to the context of quitting for Aboriginal and Torres Strait Islander smokers, is an important area for future research. ${ }^{29}$
Our finding that quitting among Aboriginal and Torres Strait Islander smokers appears to be more influenced by their perceptions that local community leaders disapprove of smoking than by disapproval by mainstream society is important. In other settings, norms from significant others are more influential on cigarette consumption and motivation to quit than are mainstream societal norms. ${ }^{24}$ In this context, significant others may include distant relatives and respected community leaders, who have been described as influential in decisions about starting to smoke among Aboriginal and Torres Strait Islander youth. ${ }^{7-9}$ This offers one explanation for the motivational effect of local Aboriginal and Torres Strait Islander leaders, although we were unable to assess whether these constructs overlap.

Further, while the survey measured perceptions about disapproval of smoking by local leaders, our findings nonetheless have implications for tobacco control leadership, and the importance of community leadership in particular. We can draw from examples of indigenous leadership and participation across all areas of tobacco control in New Zealand, ${ }^{30}$ where strong national and local Maori leadership, targeted messages and Maori approaches are seen as critical for Maori tobaccofree advances. ${ }^{31}$ There are also an increasing number of examples of community leadership in Aboriginal and Torres Strait Islander tobacco control. A 2012-2013 survey of 47
Australian organisations involved in the development of tobacco control messages for Aboriginal and Torres Strait Islander peoples showed that $32 \%$ targeted elders in these messages. ${ }^{32}$ Social marketing and other strategies that directly involve local community leaders, or shift perceptions about the beliefs of community leaders, offer a means of reinforcing beliefs that smoking is socially unacceptable and therefore strengthening motivation to quit.

We found strong support for government action to tackle the harm caused by smoking. Resistance to tobacco control is therefore not a plausible explanation for differences in quitting between Aboriginal and Torres Strait Islander peoples and other Australians. There have been similar findings for other high-prevalence populations. ${ }^{33}$

Further, while smoking may be considered somewhat more normal among Aboriginal and Torres Strait Islander smokers, we found no evidence of social norms that indicate smoking is strongly socially valued or desirable. In contrast to previous evidence that suggests social isolation of non-smokers contributes to the high smoking prevalence among Aboriginal and Torres Strait Islander peoples, $7,12,13,16$ we found that most non-smokers did not feel excluded by smokers or pressured to smoke, or that they missed out on gossip. Further, even among smokers who believed that non-smokers missed out, we found no evidence that this presents a major barrier to quitting activity.

\section{Strengths and limitations}

The TATS project dataset provides the first national, broadly representative record of normative beliefs about smoking among Aboriginal and Torres Strait Islander smokers and non-smokers.

However, this study has some limitations. Analyses of associations between normative beliefs and quitting excluded $4.8 \%$ of smokers who did not know if they wanted to quit and $1.3 \%$ who could not recall how long ago their most recent quit attempt occurred. While this removes 
3 Association of social normative beliefs about smoking with wanting and attempting to quit in a national sample of Aboriginal and Torres Strait Islander smokers*

\begin{tabular}{|c|c|c|c|c|c|c|}
\hline \multirow[b]{2}{*}{ Normative belief } & \multicolumn{3}{|c|}{ Want to quit } & \multicolumn{3}{|c|}{ Attempted to quit in the past year } \\
\hline & $\%(\text { frequency })^{\dagger}$ & Adjusted OR $(95 \% \mathrm{Cl})^{\ddagger}$ & $P^{\S}$ & 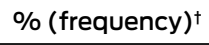 & Adjusted OR $(95 \% \mathrm{Cl})^{\ddagger}$ & $P^{s}$ \\
\hline \multicolumn{7}{|c|}{ Mainstream society disapproves of smoking } \\
\hline Neutral or disagree & $65 \%(374)$ & 1.0 & 0.01 & $46 \%(279)$ & 1.0 & 0.05 \\
\hline Agree & $73 \%(709)$ & $1.49(1.10-2.01)$ & & $51 \%(514)$ & $1.26(1.00-1.60)$ & \\
\hline \multicolumn{7}{|c|}{$\begin{array}{l}\text { Aboriginal and/or Torres Strait Islander community } \\
\text { leaders where you live disapprove of smoking }\end{array}$} \\
\hline Neutral or disagree & $64 \%(578)$ & 1.0 & $<0.001$ & $46 \%(431)$ & 1.0 & 0.001 \\
\hline Agree & $77 \%(504)$ & $1.94(1.50-2.52)$ & & $54 \%(360)$ & $1.43(1.16-1.77)$ & \\
\hline \multicolumn{7}{|c|}{$\begin{array}{l}\text { There are fewer and fewer places you feel comfortable } \\
\text { smoking }\end{array}$} \\
\hline Neutral or disagree & $64 \%(302)$ & 1.0 & 0.01 & $46 \%(224)$ & 1.0 & 0.03 \\
\hline Agree & $72 \%(781)$ & $1.45(1.09-1.93)$ & & $51 \%(569)$ & $1.33(1.03-1.71)$ & \\
\hline \multicolumn{7}{|c|}{ Non-smokers miss out on all the good gossip/yarning } \\
\hline Neutral or disagree & $70 \%(769)$ & 1.0 & 0.95 & $49 \%(564)$ & 1.0 & 0.70 \\
\hline Agree & $70 \%(314)$ & $1.01(0.75-1.36)$ & & $50 \%(229)$ & $1.05(0.82-1.34)$ & \\
\hline \multicolumn{7}{|c|}{ Being a non-smoker sets a good example to children } \\
\hline Neutral or disagree & $37 \%(54)$ & 1.0 & $<0.001$ & $33 \%(50)$ & 1.0 & 0.001 \\
\hline Agree & $73 \%(1029)$ & $4.92(2.98-8.12)$ & & $51 \%(743)$ & $2.11(1.37-3.24)$ & \\
\hline \multicolumn{7}{|c|}{$\begin{array}{l}\text { The government should do more to tackle the harm } \\
\text { done to Aboriginal and Torres Strait Islander people } \\
\text { that is caused by smoking }\end{array}$} \\
\hline Neutral or disagree & $51 \%(149)$ & 1.0 & $<0.001$ & $42 \%(129)$ & 1.0 & 0.009 \\
\hline Agree & $74 \%(934)$ & $3.03(2.17-4.23)$ & & $51 \%(663)$ & $1.48(1.10-1.98)$ & \\
\hline
\end{tabular}

uncertainties regarding the categorisation of "don't know" responses into yes/no outcomes, it also excludes a small proportion of Aboriginal and Torres Strait Islander people who may differ from included participants.

It is possible that we missed important normative beliefs that have additional influences. In particular, we did not ask specific questions about beliefs of family. This was because the diversity of family structures and a varying tendency to include distant relatives requires more extensive questioning than we had capacity for.

While it is possible that some of the differences found may be due to culturally moderated social desirability biases, we attempted to minimise the potential for this by engaging local interviewers. ${ }^{34}$ Tobacco control research in other settings suggests that survey responses about wanting to quit are not subject to greater social desirability biases when collected face to face. ${ }^{35}$
We also stress that the associations presented should not be interpreted as being causal. We cannot determine from these results alone whether negative beliefs about the social acceptability and desirability of smoking motivate quitting, or whether those motivated to quit are more likely to express negative views. While these limitations complicate our interpretations, the hypothesised causal links are strengthened by prospective research in other settings. ${ }^{21-24}$

Finally, comparisons with ITC Project data must be made with a degree of caution, given differences in methods and timing of recruitment and data collection. However, the differences we report here are too large to be accounted for by these factors.

In conclusion, tobacco control strategies that involve the leadership and participation of local Aboriginal and Torres Strait Islander community leaders, particularly strategies that emphasise protection of others, may be an important means of reinforcing beliefs that smoking is socially unacceptable, thus boosting motivation to quit.

Acknowledgements: The full list of acknowledgements is available in Appendix 2.

Competing interests: No relevant disclosures.

Provenance: Not commissioned; externally peer reviewed.

Received 31 Oct 2014, accepted 19 Mar 2015.

1 Chapman S, Freeman B. Markers of the denormalisation of smoking and the tobacco industry. Tob Control 2008; 17: 25-31.

2 Borland R. Understanding hard to maintain behaviour change: a dual process approach. Chichester, UK: John Wiley \& Sons, 2014: 102-103, 106-108, 118120, 155-159, 170-171.

3 Calma T. Tackling Indigenous smoking. Of Substance: The National Magazine on Alcohol, Tobacco and Other Drugs 2011; 9 : 28-29.

4 Council of Australian Governments. National Partnership Agreement on closing the gap in Indigenous health outcomes: implementation plan. Canberra: Commonwealth of Australia, 2009. 
5 Hyland A, Higbee C, Borland R, et al. Attitudes and beliefs about secondhand smoke and smokefree policies in four countries: findings from the International Tobacco Control Four Country Survey. Nicotine Tob Res 2009; 11: 642-649.

6 Australian Bureau of Statistics. Australian Aboriginal and Torres Strait Islander Health Survey: updated results, 2012-13. Canberra: ABS, 2014. (ABS Cat. No. 4727.0.55.006.)

7 Johnston V, Thomas DP. Smoking behaviours in a remote Australian indigenous community: the influence of family and other factors. Soc Sci Med 2008; 67: 1708-1716.

8 Johnston V, Westphal DW, Earnshaw C, Thomas DP. Starting to smoke: a qualitative study of the experiences of Australian indigenous youth. BMC Public Health 2012; 12: 963.

9 Lindorff K. Tobacco: time for action. National Aboriginal and Torres Strait Islander Tobacco Control Project. Final report. Canberra: National Aboriginal Community Controlled Health Organisation, 2002.

10 Murphy M, Mee V. The impact of the National Tobacco Campaign on Indigenous communities: a study in Victoria. In: Hassard K, editor. Australia's National Tobacco Campaign: evaluation report: vol 1. Every cigarette is doing you damage. Canberra: Commonwealth Department of Health and Aged Care, 1999: 237-253.

11 Passey ME, Gale JT, Sanson-Fisher RW. "It's almost expected": rural Australian Aboriginal women's reflections on smoking initiation and maintenance: a qualitative study. BMC Womens Health 2011; 11: 55.

12 Wood L, France K, Hunt K, et al. Indigenous women and smoking during pregnancy: knowledge, cultural contexts and barriers to cessation. Soc Sci Med 2008; 66: 2378-2389.

13 Gould GS, Munn J, Avuri S, et al. "Nobody smokes in the house if there's a new baby in it": Aboriginal perspectives on tobacco smoking in pregnancy and in the household in regional NSW Australia. Women Birth; 2013; 26: 246-253.

14 Robertson J, Pointing BS, Stevenson L, Clough AR. "We made the rule, we have to stick to it": towards effective management of environmental tobacco smoke in remote Australian Aboriginal communities. Int J Environ Res Public Health 2013; 10: 4944-4966.

15 Dawson A, Cargo M, Stewart H, et al. "I know it's bad for me and yet I do it": exploring the factors that perpetuate smoking in Aboriginal Health Workers-a qualitative study. BMC Health Serv Res 2012; 12: 102.

16 Briggs VL, Lindorff KJ, Ivers RG. Aboriginal and Torres Strait Islander Australians and tobacco. Tob Control 2003; 12 Suppl 2: ii5-ii8.

17 Thomas DP, Briggs VL, Couzos S, et al. Research methods of Talking About The Smokes: an International Tobacco Control Policy Evaluation Project study with Aboriginal and Torres Strait Islander Australians. Med J Aust 2015; 202 (10 Suppl): S5-S12.

18 Couzos S, Nicholson AK, Hunt JM, et al. Talking About The Smokes: a large-scale, communitybased participatory research project. Med J Aust 2015; 202 (10 Suppl): S13-S19.

19 Thompson ME, Fong GT, Hammond D, et al. Methods of the International Tobacco Control (ITC) Four Country Survey. Tob Control 2006; 15 Suppl 3: iiil2-iiil8.

20 StataCorp. Stata survey data reference manual: release 13. College Station, Tex: Stata Press,

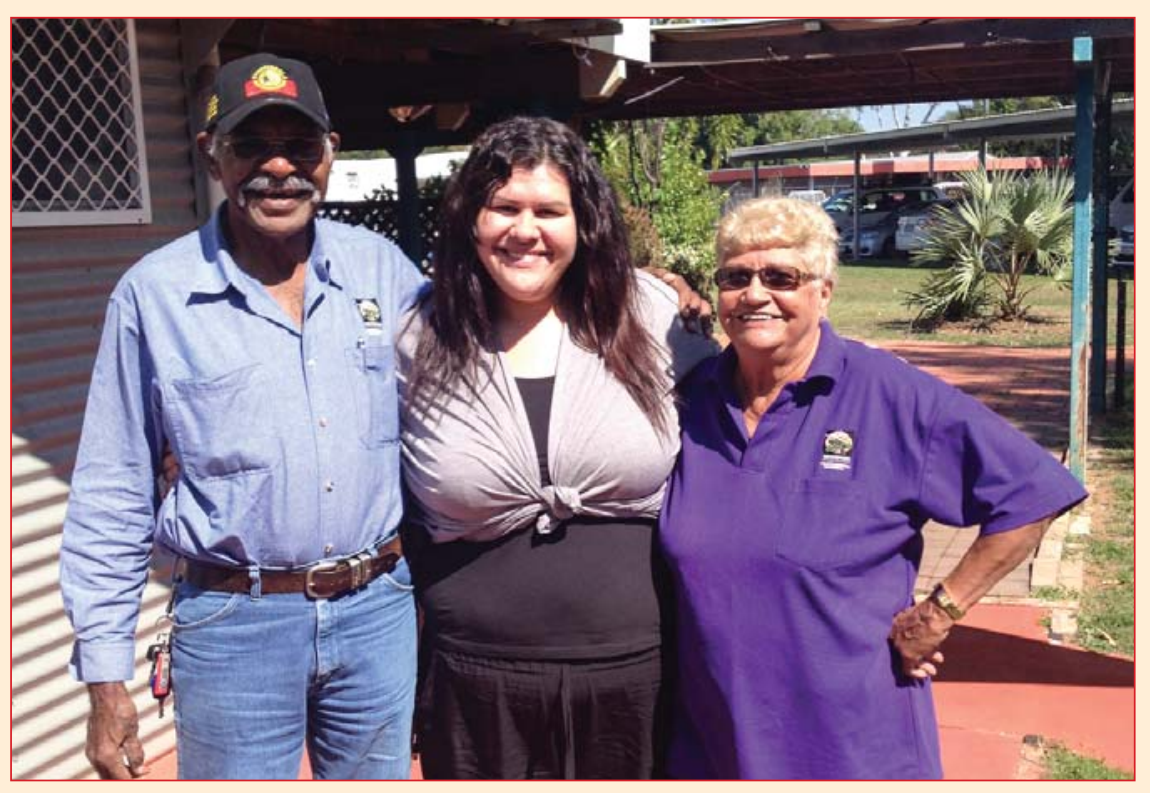

Local research assistants Francis Hayes and Ruby Stanley with TATS project coordinator Arika Errington at Wurli-Wurlinjang Aboriginal Corporation in Katherine, Northern Territory.
2013. http://www.stata.com/manualsl3/svy.pdf (accessed Apr 2015).

21 Hammond D, Fong GT, Zanna MP, et al. Tobacco denormalization and industry beliefs among smokers from four countries. Am J Prev Med 2006; 31: 225-232.

22 Biener L, Hamilton WL, Siegel M, Sullivan EM. Individual, social-normative, and policy predictors of smoking cessation: a multilevel longitudinal analysis. Am J Public Health 2010; 100: 547-554.

23 Brown A, Moodie C, Hastings G. A longitudinal study of policy effect (smoke-free legislation) on smoking norms: ITC Scotland/United Kingdom. Nicotine Tob Res 2009; 11: 924-932.

24 Hosking W, Borland R, Yong HH, et al. The effects of smoking norms and attitudes on quitting intentions in Malaysia, Thailand and four Western nations: a cross-cultural comparison. Psychol Health 2009; 24: 95-107.

25 Nicholson AK, Borland R, Bennet PT, et al. Personal attitudes towards smoking in a national sample of Aboriginal and Torres Strait Islander smokers and recent quitters. Med J Aust 2015; 202 (10 Suppl): S51-S56.

26 Thomson G, Wilson N, Weerasekera D, Edwards R. Strong smoker interest in 'setting an example to children' by quitting: national survey data. Aust $N$ Z J Public Health 2011; 35: 81-84.

27 Triandis HC. Culture and social behavior. New York: McGraw-Hill, 1994: 51.

28 Nicholson AK, Borland R, Couzos S, et al. Smoking-related knowledge and health risk beliefs in a national sample of Aboriginal and Torres Strait Islander people. Med J Aust 2015; 202 (10 Suppl): S45-S50.

29 Nicholson AK, Borland R, Davey ME, et al. Past quit attempts in a national sample of Aboriginal and Torres Strait Islander smokers. Med J Aust 2015; 202 (10 Suppl): S20-S25.

30 Blakely T, Thomson G, Wilson N, et al. The Maori Affairs Select Committee Inquiry and the road to a smokefree Aotearoa. N Z Med J 2010; 123: 7.

31 Gifford H, Parata K, Thomson G. Maori challenges and crown responsibilities: Maori policymaker ideas on smokefree policy options. N Z Med J 2010; 123: 68-76.

32 Gould GS, Watt K, Stevenson L, et al. Developing anti-tobacco messages for Australian Aboriginal and Torres Strait Islander peoples: evidence from a national cross-sectional survey. BMC Public Health 2014; 14: 250.

33 Moore K, Borland R, Yong HH, et al. Support for tobacco control interventions: do country of origin and socioeconomic status make a difference? Int J Public Health 2012; 57: 777-786.

34 International Agency for Research on Cancer. IARC handbooks of cancer prevention: tobacco control. Volume 12. Methods for evaluating tobacco control policies. Lyon: IARC, 2008: 66-68.

35 Persoskie A, Nelson WL. Just blowing smoke? Social desirability and reporting of intentions to quit smoking. Nicotine Tob Res 2013; 15: 2088-2093 - 